\title{
Communication Disorders in Individuals with HIV/AIDS
}

\author{
K. James Kallail, Ph.D. ${ }^{1,2}$, David W. Downs, Ph.D. ${ }^{2}$, Julie W. Scherz, Ph.D. ${ }^{2}$ \\ ${ }^{1}$ University of Kansas School of Medicine-Wichita \\ Department of Internal Medicine \\ ${ }^{2}$ Wichita State University \\ Department of Communication Sciences and Disorders
}

\section{Introduction}

The prevalence of communication disorders in individuals with Human Immunodeficiency Virus/Acquired Immunodeficiency Syndrome (HIV/AIDS) and how it compares to the general population are unknown. Treatment advances are being made both for individuals with communication disorders and those with HIV/AIDS. Unfortunately, little work has been done for those who have HIV/AIDS and a communication disorder. Communication disorders may have a significant impact on an individual as speech, language, and hearing often are critical to success in contemporary life. Approximately one in six Americans has some form of communication disorder. ${ }^{1}$

The natural history of HIV infection in a typical person without antiretroviral therapy from the time of HIV transmission to death is $10-11$ years. $^{2}$ The initial event is the acute retroviral syndrome accompanied by a decline in CD4 cell counts. CD4 cell count decreases are due to HIV-induced cell death. Late stage disease is characterized by a CD4 count less than 200 cells $/ \mathrm{mm}^{3}$ and development of opportunistic infections, selected tumors, wasting, and neurologic complications. However, progress treating HIV infection has decreased mortality rates and essentially made the disease a chronic condition that can be managed long term. ${ }^{3}$

The prevalence rate of HIV infection among adults and adolescents was estimated at 137.0 per 100,000 at the end of $2005 .{ }^{4}$ The prevalence of AIDS also has increased steadily since 2001 . The long-term effects of HIV/AIDS and its treatment on communication abilities raise many questions that have not been answered adequately.

\section{HIV Infection and the Central Nervous System}

HIV enters the central nervous system (CNS) early in the course of infection and its effect is widespread. Up to $100 \%$ of HIVinfected adults have CNS abnormalities. ${ }^{5}$ Prolonging life in an immunosuppressed state has resulted in increased incidence of systemic pathologies, including those of the central nervous system. If the infection progresses, various CNS pathologies appear, including opportunistic infections, primary CNS lymphoma, progressive multifocal leukoencephalopathy, peripheral or sensory neuropathy, and HIV dementia. ${ }^{3}$ Primary infection of the central nervous system occurs when there is a direct infection by HIV. Secondary CNS complications may occur due to HIV-associated systemic disorders. Secondary infection occurs when HIV infects another system in the body through an opportunistic infection, neoplasm, or systemic disorder.

\section{Cognitive and Speech-Language Disorders}

Cognitive impairment is one manifestation of the CNS complications associated with HIV/AIDS. Cognitive changes may be seen early in the course of the infection even in patients who are otherwise asymptomatic. ${ }^{3,5-6}$ Common cognitive changes include problems with 
abstract reasoning, learning difficulties, slow information processing, and retardation of the spontaneity of speech. CNS complications in patients with HIV can reflect the consequences of medical treatment. Clinicians should distinguish to the best of their knowledge between symptoms related to the HIV disease process and the side effects of antiretroviral medications. $^{3}$

HIV dementia is seen in approximately $3 \%$ of patients. $^{2}$ Although a decrease in incidence has been reported with antiretroviral therapy, the prevalence has increased because of patients surviving longer. ${ }^{7} \quad$ Slowed processing speed may underlie patient complaints related to specific cognitive deficits. ${ }^{6}$ Psychomotor slowness is associated with severity of HIV disease and occurs in the context of other HIV-related neuropsychiatric symptoms. Speech-language symptoms are related to memory loss and cognitive slowing. ${ }^{2}$ Language difficulties actually may be a manifestation of deficits in simple reaction time rather than language function. ${ }^{8}$

Primary CNS lymphomas are associated with the Epstein-Barr virus. ${ }^{2}$ The incidence is less than $6 \%$. Several symptoms relate to speech-language abilities including confusion, memory loss, and aphasia. Progressive multifocal leukoencephalopathy occurs in 1 to $2 \%$ of AIDS patients. ${ }^{2}$ Cognitive impairments and speech deficits related to hemiparesis are common symptoms. Further, up to $9 \%$ of AIDS patients are referred for psychiatric evaluations. ${ }^{2-3}$ Psychiatric illness may be associated with disorganized thinking and cognitive changes.

\section{Auditory System Disorders}

The etiologies of auditory system disorders in adults with HIV/AIDS fall into one of three broad categories: HIV/AIDS as the primary cause, opportunistic infections associated with HIV/AIDS, and iatrogenic sources. Karposi's sarcoma, for example, is the most common neoplasm in persons with HIV/AIDS. ${ }^{5}$ It is manifested on the pinna almost exclusively in persons with HIV/AIDS and may cause conductive hearing loss when manifested in the ear canal, eardrum, or middle ear. ${ }^{9}$ HIV infection also may damage the cochlea, eighth nerve, or both, sometimes resulting in sensorineural hearing loss; and it also may compromise neural pathways and centers in the brain resulting in central auditory disturbance. $^{5,10}$

Opportunistic infections due to suppressed immune systems in adults with HIV/AIDS can precipitate or exacerbate auditory disorders. These opportunistic infections include otitis media or mastoiditis in the middle ear, ${ }^{11}$ neurosyphilis, ${ }^{11-13}$ cytomegalovirus, ${ }^{14}$ cryptococcal meningitis, ${ }^{11,15}$ non-Hodgkin's lymphoma in the oral cavity, ${ }^{5}$ pharyngeal infections associated with hemophilia-A, ${ }^{16}$ and several other infections of the head and neck. ${ }^{10,17-18}$ Adults with HIV/AIDS may show head, neck and otologic symptoms from opportunistic infections, including otalgia, otorrhea, tinnitus, "muffled" hearing, aural fullness, facial nerve palsy, vertigo and central vestibular, and ocular-motor disturbance. $^{5,10-11,17-25}$

Ototoxicity from drugs used to treat adults with HIV/AIDS is the most common iatrogenic source of auditory disorders. Tseng and colleagues ${ }^{26}$ found that $17 \%$ of HIV/AIDS patients who received azithromycin experienced drug-related hearing problems and three-fourths of these problems resolved after azithromycin was discontinued. Kohan and colleagues ${ }^{20}$ reported on seven patients with HIV/AIDS who had persistent sensorineural hearing losses. Three patients had been exposed repeatedly to strong ototoxic drugs (i.e., aminoglycosides), while the other four had 
persistent hearing losses despite standard antibiotic treatments. Simdon and colleagues $^{27}$ reported three cases of auditory dysfunction, possibly associated with nucleoside analog reverse transcriptase inhibitors. All three patients had histories of noise-induced hearing loss and tinnitus that worsened during antiretroviral therapy. Marra and colleagues ${ }^{11}$ also reported that hearing loss was associated with antiretroviral therapy in subjects with HIV/AIDS, particularly subjects 35 years or older.

Whatever the etiology, some middle ear infections in adults with HIV/AIDS, such as chronic otitis media, supporative otitis media, and mastoiditis, are as common as those in adults without HIV/AIDS and often respond to medical treatment as well. ${ }^{10,22}$ Conversely, pneumocystis carinii otitis media is an opportunistic infection unique to persons with HIV disease and can cause conductive or mixed hearing losses. ${ }^{5,10}$

Sensorineural hearing loss, which often cannot be treated medically, is more common among adults with than those without HIV/AIDS. ${ }^{10,18,20,28}$ The likelihood of sensorineural hearing loss among adults with HIV/AIDS varies among studies depending on the characteristics of the sample and the criteria for hearing loss. In general, sensorineural hearing losses occurred in one-third to two-thirds of the subjects. They usually occurred more at high frequencies than at low frequencies and were more severe in patients with more severe HIV infections ${ }^{17}$ or, similarly, with greater deterioration in immunologic status $^{28}$. Furthermore, most neuro-otological disorders in HIV/AIDS patients have a central origin; both central auditory disorders and peripheral auditory disorders are more common in advanced stages of HIV/AIDS. ${ }^{21,29-30}$ Central auditory disorders also may be more common in adults with HIV-Associated Dementia ${ }^{31}$, though research in this area is lacking. Finally, common risk factors for hearing loss in adults in general (e.g., excessive noise exposure or aging) can impact the prevalence and severity of auditory problems in adults with HIV/AIDS.

\section{Audiological Testing}

Although HIV/AIDS can manifest problems at all levels of the auditory system, a limited variety of audiologic tests have been used to measure auditory function in the HIV/AIDS population. Clearly, the most common measure has been auditory evoked potentials, an EEG type of test in which the presence of brainwaves are recorded to predominantly non-speech sounds. Although a small number of researchers have recorded evoked responses from the upper brainstem, thalamus, and cortex, ${ }^{32-33}$ most have used auditory brainstem response (ABR) testing which measures neural responses mainly from the eighth nerve and lower and mid brainstem..$^{10,25,31,34-43}$ The emphasis on ABR testing may arise from its ability to detect early clinical and subclinical pathologic changes in the eighth nerve and brainstem of adults with HIV/AIDS. ${ }^{34-36,43}$ Larson $^{5}$ advocated that the evaluation of hearing loss in the patient with AIDS should be approached as an eighth nerve neuropathy. She suggested that audiologists complete a test battery including pure tone testing, speech audiometry, tympanometry, acoustic reflex testing, and ABR testing.

Larson's proposed auditory test battery is more extensive than most researchers have used in studies of audition in patients with HIV/AIDS. ${ }^{5}$ Nevertheless, by focusing on measuring eighth nerve neuropathology, Larson's battery may not be comprehensive enough to track the variety of auditory problems encountered with HIV/AIDS in adults. Her battery did not include any measures of social-emotional manifestations 
of hearing loss, which may be even more prominent when it accompanies HIV/AIDS. One popular valid measure of social and emotional problems that has been used with adults without HIV/AIDS is the Hearing Handicap Inventory for Adults. ${ }^{44}$ If Larson proposed her battery today, moreover, it likely would include otoacoustic emissions testing. This is an electro-acoustic measure of the cochlea's outer hair cell function which can be compromised by ototoxic drugs. ${ }^{45}$

The most prominent omissions in Larson's battery are behavioral auditory tests of central auditory processing. Recent professional guidelines of the AmericanSpeech-Language-Hearing Association ${ }^{46}$ mandate that behavioral measures are essential for diagnosing central auditory processing disorders; conversely, they cannot be diagnosed by electrophysiological measures alone.

The most widely researched behavioral test battery of central auditory processing disorders in adults was developed over several decades by an audiologist, James Jerger, and his colleagues. ${ }^{47-55}$ It employs performance-intensity functions for both monosyllabic words, performance-intensity functions for scrambled sentences presented to the same ear in noise (i.e., Synthetic Sentence Identification for ipsilateral competing messages or SSI-ICM), and scrambled sentences presented simultaneously in both ears (i.e., dichotic sentence identification or DSI). This battery can differentiate auditory disorders between the cochlea, eighth nerve, brainstem, and temporal lobe. This battery contains the essential elements in any successful central auditory test battery, efficient and effective controls over cochlear sensitivity loss, absolute speech recognition ability, and nonauditory influences. ${ }^{54}$

The SSI-ICM and DSI have been used to diagnose central auditory processing disorders in subjects with varying degrees of brain damage. ${ }^{56}$ To our knowledge, however, a case study of an adult with AIDS and organic brain disease was the only study of these measures in a subject with HIV/AIDS. ${ }^{30}$ The patient showed abnormally reduced scores on in both ears on the SSI-ICM.

As radiographic technology, such as magnetic resonance imaging, has improved over the past two decades, many audiology facilities serving adults no longer routinely use relatively expensive ABR testing for diagnosing space-occupying lesions. Conversely, nearly all audiology clinics in the United States have personnel, equipment, and materials to complete pure tone testing, speech audiometry, tympanometry, acoustic reflex testing, otoacoustic emissions testing, and the Hearing Handicap Inventory for Adults. In other words, nearly all audiologists have the capability to evaluate, in about two hours, both peripheral and central auditory function of adults with HIV/AIDS. Such a feasible, yet comprehensive, test battery may become more vital for tracking auditory problems of adults with HIV/AIDS as they live longer and grow in numbers. No researchers, however, have studied such a comprehensive test battery in HIV/AIDS patients systematically.

\section{Summary}

Speech, language, and hearing disorders are not uncommon in individuals with HIV/AIDS. Little research, however, has explored the relationship and impact between HIV/AIDS and communication abilities. Several factors related to HIV/AIDS influence communication abilities. These factors include CNS abnormalities related to the infection, opportunistic infection, and treatment effects. Clinicians should distinguish to the best of their knowledge between symptoms 
related to the HIV disease process and the side effects of antiretroviral medications. Assessments of communication disorders should be obtained as necessary to provide

\section{References}

${ }^{1}$ National Institute on Deafness and Other Communication Disorders. NIDCD Health Disparities Strategic Plan Fiscal Years 2004-2008. Accessed at: http:// www.nidcd.nih.gov/about/plans/strategic/ health_disp.asp.

2 Bartlett JG, Gallant JE. 2005-2006 Medical Management of HIV Infection. Baltimore: Johns Hopkins Medicine Health Publishing Business Group, 2005.

3 Treisman GJ, Kaplin AI. Neurologic and psychiatric complications of antiretroviral agents. AIDS 2002; 16:1201-1215.

${ }^{4}$ Centers for Disease Control and Prevention. Surveillance Report, 2005. Vol. 17. Rev ed. Atlanta: U.S. Department of Health and Human Services, Centers for Disease Control and Prevention; 2007. Accessed at: http://www.cdc.gov/hiv/ topics/surveillance/resources/reports/.

${ }^{5}$ Larsen CR. HIV-1 and Communication Disorders: What Speech and Hearing Professionals Need to Know. San Diego: Singular Publishing Group, 1998.

${ }^{6}$ Lopez OL, Wess J, Sanchez J, Dew MA, Becker JT. Neurobehavioral correlates of perceived mental and motor slowness in HIV infection and AIDS. J Neuropsychiatry Clin Neurosci 1998; 10:343-350.

${ }^{7}$ Dore GJ, McDonald A, Yueming L, Kaldor JM, Brew BJ. Marked improvement in survival following AIDS dementia complex in the ears of highly active antiretroviral therapy. AIDS 2003; 17:1539-1545.

${ }^{8}$ Mapou RL, Law WA, Martin A, Kampen D, Salazar AM, Rundell JR. Neuropsychological performance, mood, quality care to individuals with HIV/AIDS and to maintain the quality of life that effective communication provides.

and complaints of cognitive and motor difficulties in individuals infected with the human immunodeficiency virus. J Neuropsychiatry Clin Neurosci 1997; 9:37-44.

${ }^{9}$ Marcusen DC, Sooy CD. Otolaryngologic and head and neck manifestations of acquired immunodeficiency syndrome (AIDS). Laryngoscope 1985; 95:401-405.

${ }^{10}$ Lalwani AK, Sooy CD. Otologic and neurotologic manifestations of Acquired Immunodeficiency Syndrome. Otolaryngol Clin North Am 1992; 25:1183-1197.

${ }^{11}$ Marra CM, Wechkin HA, Longstreth Jr WT, Rees TS, Syapin CL, Gates GA. Hearing loss and antiretroviral therapy in patients infected with HIV-1. Arch Neurol 1997; 54:407-410.

${ }^{12}$ Little JP, Gardner G, Acker JD, Land MA. Otosyphilis in a patient with human immunodeficiency virus: Internal auditory canal gumma. Otolaryngol Head Neck Surg 1995; 112:488-492.

${ }^{13}$ Dreier A, Martinez V, Jimenez ML, Orus C, Jurgens A, Amesti C. Sudden bilateral deafness of luetic origin in an HIVpositive patient. Acta Otorrinolaringol Esp 1993; 44:315-317.

${ }^{14}$ Meynard JL, El Amrani M, Meyohas MC, et al. Two cases of cytomegalo-virus infection revealed by hearing loss in HIVinfected patients. Biomed Pharmacother 1997; 51:461-463.

${ }^{15}$ Kwartler JA, Linthicum FH, Jahn AF, Hawke M. Sudden hearing loss due to AIDS-related cryptococcal meningitis: A temporal bone study. Otolaryngol Head Neck Surg 1991; 104:265-269. 
${ }^{16}$ Ohashi S, Hirade F, Funasaka S, et al. Two cases of sensory neural hearing loss as a manifestation of HIV infection. Nippon Jibiinkoka Gakkai Kaiho 1995; 98:1399-1406.

${ }^{17}$ Chandrasekhar SS, Connelly PE, Brahmbhatt SS, Shah CS, Kloser PC, Baredes S. Otologic and audiologic evaluation of Human Immunodeficiency Virus-infected patients. Am J Otolaryngol 2000; 21:1-9.

${ }^{18}$ Moazzez AH, Alvi A. Head and neck manifestations of AIDS in adults. Am Fam Physician 1998; 57:1813-1822.

${ }^{19}$ Soucek S, Michaels L. The ear in the Acquired Immunodeficiency Syndrome: II. Clinical and audiologic investigation. Am J Otol 1996; 17:35-39.

${ }^{20}$ Kohan D, Rothstein SG, Cohen NL. Otologic disease in patients with Acquired Immunodeficiency Syndrome. Ann Otol Rhinol Laryngol 1988; 97:636-640.

${ }^{21}$ Hausler R, Vibert D, Koralnik IJ, Hirschel B. Neuro-otological manifestations in different stages of HIV infection. Acta Otolaryngol Suppl 1991; 481:515-521.

${ }^{22}$ Gold S, Tami TA. Otolaryngological manifestations of HIV/AIDS. Semin Hear 1998; 19:165-175.

${ }^{23}$ Jacquet Y, Maire R. Otoneurologic manifestations related to HIV infection: Case report of facial paralysis and review of the literature. Rev Med Suisse Romande 2002; 122:269-71.

${ }^{24}$ Domenech J, Fuste J, Traserra J. Equilibrium and auditory disorders in patients affected by HIV-1. Rev Neurol 1996; 24:1623-1626.

${ }^{25}$ Rosenhall U, Hakansson C, Lowhagen GB, Hanner P, Jonsson-Ehk B. Otoneurological abnormalities in asymptomatic HIV-seropositive patients. Acta Neurol Scand 1989; 79:140-145.

${ }^{26}$ Tseng AL, Dolovich L, Salit IE. Azithromycin-related ototoxicity in patients infected with Human
Immunodeficiency Virus. Clin Infect Dis 1997; 24:77-78.

${ }^{27}$ Simdon J, Watters D, Barlett S, Connick E. Ototoxicity associated with use of nucleoside analog reverse transcriptase inhibitors: A report of 3 possible cases and review of the literature. Clin Infect Dis 1991; 32:1623-1627.

${ }^{28}$ Khoza K, Ross E. Auditory function in a group of adults infected with HIV/AIDS in Gauteng, South Africa. S Afr J Commun Disord 2002; 49:17-27.

${ }^{29}$ Hoistad DL, Hain TC. Central hearing loss with a bilateral inferior colliculus lesion. Audiol Neurootol 2003; 8:111-113.

${ }^{30}$ Hart CW, Cokely CG, Schupbach J, Dal Canto MC, Coppleson LW. Neurotologic findings of a patient with Acquired Immune Deficiency Syndrome. Ear Hear 1989; 10:68-76.

${ }^{31}$ Bankaitis AE, Christensen LA, Murphy G, Morehouse CR. HIV/AIDS and auditory evoked potentials. Semin Hear 1998; 19:177-193.

${ }^{32}$ Matas CG, de Juan KR, Nakano RA. Middle and late latency auditory evoked potentials in adults with AIDS. Pro Fono 2006; 18:171-176.

${ }^{33}$ Handelsman L, Horvath T, Aronson M, et al. Auditory event-related potentials in HIV-1 infection: A study in the drug-user risk group. $\mathbf{J}$ Neuropsychiatry Clin Neurosci 1992; 4:294-302.

${ }^{34}$ Reyes-Contreras L, Silva-Rojas A, Ysunza-Rivera A, Jimenez-Ruiz G, Berruecos-Villalobos P, Gutierrez G. Brainstem auditory evoked response in HIV-infected patients with and without AIDS. Arch Med Res 2002; 33:25-28.

${ }^{35}$ Welkoborsky HJ, Lowitzsch K. Auditory brain stem responses in patients with Human Immunotropic Virus infection of different stages. Ear Hear 1992; 13:55-57.

${ }^{36}$ Birchall MA, Wight RG, French PD, Cockbain Z, Smith SJ. Auditory function in patients infected with the human 
immunodeficiency virus. Clin Otolaryngol Allied Sci 1992; 17:117-121.

${ }^{37}$ Bankaitis AE. The effects of click rate on the auditory brain stem response (ABR) in patients with varying degrees of HIVinfection. Ear Hear 1995; 16:321-324.

${ }^{38}$ Christensen LA, Morehouse CR, Powell TW, Alchediak T, Silio M. Antiviral therapy in a child with pediatric human immunodeficiency virus (HIV): Case study of audiologic findings. J Am Acad Audiol 1998; 9:292-298.

${ }^{39}$ Mata Castro N, Yebra Bango M, Tutor de Ureta P, Vellarreal Garcia-Lomas M, Garcia Lopez F. Hearing loss and human immunodeficiency virus infection. Study of 30 patients. Rev Clin Esp 2000; 200:371-274.

${ }^{40}$ Ohtsuka Y. Characteristics of auditory brainstem response in presbyacusis Compared with the results of pure tone, speech or binaural audiometry. Nippon Jibiinkoka Gakkai Kaiho 1996; 99:17641771.

${ }^{41}$ Pierelli F, Soldati G, Zambardi P, et al. Electrophysiological study (VEP, BAEP) in HIV-1 seropositive patients with and without AIDS. Acta Neurol Belg 1993; 93:78-87.

${ }^{42}$ Pagano MA, Cahn PE, Garau ML, et al. Brain-stem auditory evoked potentials in human immunodeficiency virus seropositive patients with and without acquired immunodeficiency syndrome. Arch Neurol 1992; 49:166-169.

${ }^{43}$ Castillo E, Baroni N, Pallestrini E. Neurological auditory brain stem response findings in human immunodeficiency virus-positive patients without neurologic manifestations. Ann Otol Rhinol Laryngol 1998; 107:1054-1060.

${ }^{44}$ Newman CW, Weinstein BE, Jacobson GP, Hug GA. Test-retest reliability of the hearing handicap inventory for adults. Ear Hear 1991; 12:355-7.
${ }^{45}$ Harris FP, Probst R. Otoacoustic emissions and audiometric outcomes. In: MS Roinette and TJ Glattke, Eds, Otoacoustic Emissions: Clinical Applications. New York: Thieme, 1997.

${ }^{46}$ American Speech - Language - Hearing Association. (Central) Auditory Processing Disorders. Rockville, MD: ASHA, 2005. Accessed at: http://www.asha.org/NR/rdonlyres/8A220 4DE-EE09-443C-98AA-3722C18214E3/ 0/v2PS_CAPD.pdf.

${ }^{47}$ Fifer RC, Jerger JF, Berlin CI, Tobey EA, Campbell JC. Development of a dichotic sentence identification test for hearingimpaired adults. Ear Hear 1983; 4:300305.

${ }^{48}$ Jerger J, Chmiel R, Allen J, Wilson A. Effects of age and gender on dichotic sentence identification. Ear Hear 1994; 15:274-286.

${ }^{49}$ Jerger J, Hayes D. Diagnostic speech audiometry. Arch Otolaryngol 1977; 103:216-222.

${ }^{50}$ Jerger J, Jerger S. Clinical validity of central auditory tests. Scand Audiol 1975; 4:147-163.

${ }^{51}$ Jerger J, Martin J. Dichotic listening tests in the assessment of auditory processing disorders. Audiological Medicine 2006; 4:25-34.

${ }^{52}$ Jerger J, Speaks C, Trammel JL. A new approach to speech audiometry. J Speech Hear Disord 1968; 33:319-328.

${ }^{53}$ Jerger S, Jerger J. Neuroaudiologic findings in patients with central auditory disorders. Semin Hear 1983; 4:133-159.

${ }^{54}$ Stach BA. Diagnosing central auditory processing disorders in adults. In RJ Roeser, M Valente, H Hosford-Dunn, Eds., Audiology Diagnosis. New York: Thieme, 2000.

${ }^{55}$ Stach, BA, Spretnjak ML, Jerger J. The prevalence of central presbyacusis in a clinical population. J Am Acad Audiol 1990; 1:109-115. 
${ }^{56}$ Strouse AL, Hall JW, Burger MC. Central auditory processing in Alzheimer's Disease. Ear Hear 1995; 16:230-238.

Keywords: Human Immunodeficiency Virus, Acquired Immunodeficiency Syndrome, communication disorders, speech disorders, language disorders, hearing disorders, dementia 